\title{
A Alca e as novas alianças sindicais Norte-Sul
}

\author{
YVES CHALOULT * \\ WILSON FERNÁNDEZ**
}

\section{O sindicalismo dos Estados Unidos ante a globalização}

O movimento sindical norte-americano tem procurado, através de suas diversas organizações, defender-se da instabilidade do trabalho que se instalou naquele país nas três últimas décadas, em virtude das transformações tecnológicas e do surgimento de novos competidores internacionais. Tal situação o tem levado a participar com força considerável nos debates realizados sobre a política comercial aplicada pelo governo dos EUA.

Entre os anos 30 e 50, os sindicatos norte-americanos apoiaram a liberalização comercial. Eram os anos do grande desenvolvimento industrial da América. Posteriormente, à medida que as indústrias iam perdendo competitividade internacional, foram mudando de posição e por volta de 1980 a American Federation of Labor - Congress of Industrial Organizations (AFL-CIO) se "opunha firmemente a uma maior abertura do mercado norte-americano" (Sela, 1998).

Processos como a perda de mercados tradicionais sofrida por algumas grandes empresas, a reconversão tecnológica de outras sem uma adequada requalificação de sua mão-de-obra e as estratégias de internacionalização da produção adotadas por outras mais (às vezes em função de custos inferiores da força de trabalho em outros países) são alguns dos fenômenos que têm ocasionado a perda de postos de trabalho ou a transferência dos mesmos para o exterior. Tudo isso tem feito com que os sindicatos, liderados pela central sindical AFL-CIO, procurem responder às decisões do governo americano adotando posturas fortemente protecionistas.

Os seguidos fracassos das estratégias adotadas pela AFL-CIO, quando estas postulavam unicamente opções radicais do tipo "sim" ou "não", levaram

\footnotetext{
Rev. Bras. Polit. Int. 44 (2): 168-185 [2001]

* Yves Chaloult, Ph.D. em Sociologia do Desenvolvimento pela Universidade de Cornell, EUA, é professor do Departamento de Sociologia da Universidade de Brasília (UnB).

** Wilson Fernández, doutor em Sociologia pelo Centro de Pesquisa e Pós-Graduação sobre a América Latina e Caribe (CEPPAC) da UnB, é professor de Relações Internacionais na Faculdade de Direito da Universidade da República, Montevidéu, Uruguai.
} 
seus dirigentes a mudar de tática. A central passou, então, a propor a modificação daquelas iniciativas que não podia bloquear por completo, exigindo dos países participantes dos acordos o respeito aos direitos trabalhistas.

Muito significativo a esse respeito foi a incorporação ao Acordo de Livre Comércio da América do Norte (mais conhecido por sua sigla em inglês, Nafta, North American Free Trade Agreement) de um acordo adicional, o North American Agreement on Labor Cooperation (NAALC). Esse novo tratado, nas palavras do governo norte-americano, "seeks to promote fundamental labor standards, compliance with labor laws, and the enforcement of those laws in each country" (USTR, 1997a: chap. 3). Juntamente com um novo e importante aliado proveniente da sociedade civil - o movimento ecologista -, os sindicatos dos EUA haverão de desempenhar novamente um papel fundamental no debate entre "protecionismo" e "livre comércio", procurando limitar a autonomia governamental na negociação de novos acordos comerciais (Sela, 1998). Tanto esse acordo trabalhista como o que foi celebrado a respeito da proteção do meio ambiente são considerados pelos dirigentes sindicais e pelos ecologistas como dois dos maiores êxitos alcançados por suas organizações na luta contra a perda de fontes de trabalho e a deterioração ambiental.

Essa transformação da linha estratégica relativa à maneira de enfrentar os desafios da globalização - que também estava fazendo sentir o efeito de suas transformações sobre a economia norte-americana e o emprego dos norteamericanos - foi acompanhada de uma mudança radical tanto na cúpula da direção como na orientação política da central sindical. A AFL-CIO havia visto diminuir o número de seus membros de maneira alarmante nas últimas décadas: o número de trabalhadores sindicalizados caíra de um máximo de $35 \%$ nos anos 50 para apenas $10 \%$ em inícios da última década do século. A constatação, de Zoveida SerranoJenkins, representante da AFL-CIO para o Cone Sul, foi expressa em entrevista concedida a um destes autores por ocasião da reunião da Coordenadora de Centrais Sindicais do Cone Sul (CCSCS) realizada em Montevidéu, Uruguai, em dezembro de 1999 (Serrano-Jenkins, 1999).

O aumento do desemprego dos anos 70 e 80, a crescente flexibilização do trabalho e a conseqüente instabilidade deste, a incorporação de novas tecnologias - cada vez mais poupadoras de mão-de-obra-, a concorrência externa que sofriam as principais indústrias norte-americanas, o estabelecimento do Nafta e os processos de relocalização industrial no exterior - que, na realidade, eram anteriores ao acordo de livre comércio com o México e o Canadá, mas que desde então se acentuaram - provocaram uma revisão da orientação sindical que, como veremos posteriormente, implicou também a busca de novas alianças com os trabalhadores sindicalizados da América Latina, como forma de enfrentar conjuntamente os impactos negativos da globalização (Serrano-Jenkins, 1999). 


\section{O movimento sindical e o fracasso da solicitação da Fast Track Authority}

A mudança de estratégia da AFL-CIO é uma das chaves a que se recorre para explicar o fracasso do governo Clinton na busca de autorização do Congresso dos Estados Unidos para atuar pela via rápida na concretização de acordos comerciais com outros países (permissão conhecida como Fast Track Authority ${ }^{1}$ ), o que redundou, ao menos por ora, no retardamento da implementação da Área de Livre Comércio das Américas (Alca).

Em novembro de 1997, o governo de Bill Clinton sofreu o revés mais duro de sua política comercial internacional, ao não conseguir os votos necessários, dentro de seu próprio partido, para aprovar a Fast Track Authority que havia solicitado. Isso obrigou o Executivo a retirar a solicitação feita, para evitar assim uma derrota humilhante. Naquele momento, a autorização do Congresso seria usada para implementar os respectivos acordos de livre comércio com o Chile e logo com os países americanos no âmbito, proposto em dezembro de 1994, da Alca.

Para sublinhar a importância desse fracasso, cabe recordar que o presidente Clinton foi o primeiro mandatário democrata reeleito desde os tempos de Lyndon Johnson (que, aliás, era vice-presidente, tendo assumido pela primeira vez após o assassinato de John Kennedy), na década de 70, devendo-se sua reeleição ao notável melhoramento da maioria dos indicadores econômicos dos Estados Unidos durante sua primeira administração, incluída uma importante queda do desemprego.

Não obstante todos esses antecedentes favoráveis, o Congresso norteamericano não concedeu a autorização da "via rápida" solicitada pela Casa Branca. Não era a primeira vez que isso ocorria com o presidente Clinton, mas haveria de ser a definitiva no que tange a seus dois mandatos já que, com esse precedente, tampouco em 1998 o projeto obteria os votos necessários, razão pela qual foi novamente retirado da apreciação do Congresso, procurando-se assim evitar uma nova derrota presidencial no momento em que a imagem de Clinton deteriorava-se por outros motivos. Quando, em fins de 1998, o tema voltou a ser considerado pelo Congresso dos EUA, já haviam transcorrido as eleições legislativas da segunda parte do mandato do presidente e conseqüentemente já estava demasiado próximo o período em que a atenção partidária ia estar concentrada nas pré-candidaturas para a sucessão presidencial de 2000, sendo que uma derrota no Congresso afetaria não somente o presidente Clinton mas também o seu partido, em especial quando já se especulava sobre a postulação certa de seu vice-presidente, Al Gore. Desse modo, o tema da autorização da via rápida para negociar acordos como a Alca restou momentaneamente deixado de lado.

Um documento elaborado pelo Sistema Econômico Latino-Americano (Sela) esgrime três razões para explicar o repúdio à solicitação presidencial. Em ordem decrescente de importância, estas três razões seriam: a) as dificuldades para resolver as diferenças no interior dos partidos em torno dos temas dos direitos 
trabalhistas e do meio ambiente; b) "a incapacidade dos líderes republicanos no Congresso em reconhecer a importância de fazer concessões políticas sobre o conteúdo do projeto comercial"; c) os equívocos cometidos tanto pela Presidência como pelo Congresso (Sela, 1998).

Enquanto os dois últimos fatores se referem a aspectos da luta pelo poder dentro do aparelho estatal norte-americano, o primeiro está determinado pela ação da sociedade civil. Por esse motivo, e dado o interesse que para nossa argumentação tem o primeiro dos pontos assinalados, faremos um percurso inverso, começando pelo que o documento do Sela chama de "os equívocos" da Casa Branca e do Congresso. Em que consistem tais equívocos, segundo o documento do Sela? Basicamente, em três questões.

Em primeiro lugar, como resultado da aprovação do Nafta em 1993, os eleitores do Partido Democrata manifestaram seu repúdio nas eleições legislativas de 1994, com o que o partido do presidente Clinton perdeu a maioria em ambas as câmaras do Congresso, depois de muitas décadas de controle do mesmo. Embora tenha recuperado o controle do Senado posteriormente, o partido voltou a ficar em minoria na Câmara de Representantes nas eleições de 1996 e 1998. Essa situação o debilitou desde então, passando o partido a necessitar dos votos dos republicanos para poder obter a autorização pretendida. ${ }^{2}$

Em segundo lugar, os prazos eleitorais presidenciais nos Estados Unidos têm-se encurtado, e a disputa pelas indicações partidárias começa já desde o início de cada período de governo. Desse modo, os aspirantes à indicação pelo Partido Republicano - em particular Newt Gingrich, líder do partido no Congresso durante as sucessivas administrações de Bill Clinton - desenvolviam uma campanha tendente tanto a assegurar suas posições com vistas a uma previsível futura postulação por seu partido, como a dividir seus rivais democratas. Por seu lado, dentro do partido do presidente Clinton, também existia uma atitude não colaboracionista com o Poder Executivo, principalmente por parte de Richard Gephardt, líder da minoria na Câmara de Representantes. Gephardt havia sido pré-candidato em 1988 e ainda mantinha vivas suas aspirações, eventualmente para o ano 2000. Enquanto Gingrich estava ligado partidariamente aos setores empresariais que postulavam o livre comércio, durante os anos 80 Gephardt havia sido "o principal porta-voz dos interesses protecionistas", mantendo sua preocupação em relação aos temas trabalhistas e ambientalistas.

Por último, o presidente Clinton, mesmo tendo oscilado entre uma postura discretamente favorável ao livre comércio no início de seu primeiro mandato e um envolvimento maior com essa posição quando começava o segundo, não perseverou em suas postulações a favor da obtenção da autorização para a via rápida, que lhe teria permitido avançar na consecução de novos acordos comerciais sem maior intervenção do Congresso. A isso se somaram reiterados atrasos na apresentação de dois informes - considerados cruciais - que a Representante Comercial dos 
Estados Unidos estava obrigada a entregar ao Congresso. No primeiro deles devia avaliar-se o funcionamento dos três primeiros anos do Nafta, ao passo que o segundo deveria apontar as perspectivas que se abriam em torno dos diversos acordos comerciais que os EUA tinham em gestação (USTR, 1997a e 1997b).

Para agravar ainda mais a situação, a cerimônia de apresentação oficial da solicitação de fast track estava prevista e foi realizada em 10 de setembro de 1997, contudo o documento final só ficou pronto seis dias depois, o que representou um fiasco ponderável para a administração Clinton (Sela, 1998). Em reação ao episódio, um importante jornal de Washington, muito ligado aos interesses dos grupos pró-livre comércio, em editorial intitulado "Who lost fast-track?", responsabilizava sobretudo o presidente Clinton pela derrota do projeto (The Washington Times, 1997).

O tema concernente à incapacidade dos líderes do Partido Republicano em flexibilizar suas posições e lograr acordos que teriam permitido a aprovação da fast track, tal como era sua intenção, é também um assunto vinculado ao sistema do toma-lá-dá-cá prevalecente no funcionamento do Congresso dos EUA. As leis comerciais das três últimas décadas do século que findou sempre foram apresentadas incluindo outros assuntos que eram de interesse para determinados congressistas, quer estivessem agindo conjuntamente em grupos de interesse ou atuando de forma individual. Nessa ocasião, o presidente do Comitê de Meios e Arbitragem, Bill Archer, preferiu não utilizar este sistema, "insistindo em que se redigisse uma lei 'limpa' que não estivesse carregada com o que ele considerava assuntos estranhos". Ao apresentar-se assim, não houve possibilidade de incluir os temas trabalhistas e ambientais que interessavam aos legisladores democratas, já que tanto Archer como seus colegas de partido se opunham ferreamente a isto. A falta de flexibilidade de Archer levou também a que outros assuntos que poderiam ter estado na negociação - e que interessavam tanto ao Conclave de Congressistas Negros (Congressional Black Caucus), que contava com 39 membros, como aos legisladores de origem hispano-americana, com outros 18 representantes -se frustrassem igualmente (Sela, 1998).

\section{Peso dos sindicatos e da sociedade civil}

Por último, enfoca-se o fator mais importante do processo: o peso da intervenção da AFL-CIO e de outros setores da sociedade civil - tais como as organizações não-governamentais de caráter ambientalista, de consumidores, etc. - no debate sobre o Nafta, o livre comércio e o protecionismo e, em definitivo, sobre a autorização da Fast Track Authority ao presidente Clinton.

Como assinalamos anteriormente, à medida que a economia norte-americana começou a enfrentar problemas de competitividade internacional, especialmente desde meados da década de 60 , os trabalhadores sindicalizados começaram a 
opor-se à liberalização comercial que, em outras épocas, haviam apoiado decididamente. Esta mudança de atitude se fez mais notória a partir dos anos 80 . No entanto, as estratégias utilizadas até essa época, de "tudo ou nada", não impediram que se fossem acumulando medidas de livre comércio. Os sindicalistas mudaram então a forma de encarar o tema, passando a propor modificações naquelas iniciativas que não podiam bloquear. A nova estratégia deu melhores resultados e, desde a discussão da Iniciativa para o Caribe, e em seguida para a renovação do Sistema Generalizado de Preferências (SGP), os sindicalistas lograram condicionar as preferências comerciais ao respeito dos direitos trabalhistas por parte dos países beneficiados pelas concessões norte-americanas.

Por esse tempo, os efeitos da globalização começaram a se fazer sentir de maneira cada vez mais aguda nos Estados Unidos. As maiores empresas industriais, onde os sindicatos e a central AFL-CIO tinham maior poder de convocação, começaram a voltar-se cada vez mais em direção do mercado internacional, subordinando-se à dinâmica financeira. Os empresários começaram, por um lado, um processo de "relocalização industrial" em países periféricos e, por outro, a tecnificar cada vez mais sua produção.

Ambos elementos atuaram sobre o mercado de trabalho norte-americano, diminuindo o número de empregos industriais e, em conseqüência, o número de afiliados da central sindical. A relocalização industrial se dirigia àqueles países onde os custos de mão-de-obra eram menores, as leis trabalhistas inexistiam ou não eram respeitadas e as regulações sobre o funcionamento das empresas eram muito menos rigorosas (Minián, 1989). Esse processo logo começaria a reverterse à medida que o componente de capital intelectual necessário para a produção se ia acrescentando, como resultado das transformações científico-tecnológicas da última parte do século recém-findo (Minián, 1990).

Os compromissos anteriormente firmados com os trabalhadores (contratação coletiva, seguridade do trabalho, benefícios sociais, etc.) começaram a deixar de ser cumpridos pelos empregadores, que agora tinham como prioridade os novos desafios de produtividade e competitividade internacional, os quais muitas vezes eram promovidos pelas mesmas empresas através de suas filiais.

$\mathrm{O}$ aumento da flexibilidade e da mobilidade do trabalho e um crescente desemprego estrutural permitiram aos empresários pressionar cada vez mais os trabalhadores, que começaram a ver-se submetidos a uma rápida perda das qualificações adquiridas no passado, de sorte que, para se manterem em atividade, tornou-se-lhes imprescindível uma permanente luta pela requalificação. A terceirização do trabalho, a expansão do emprego no domicílio graças às novas técnicas que possibilitam a comunicação on-line com a empresa, etc., foram debilitando crescentemente o poderio dos sindicatos e sua capacidade reivindicativa. Em poucos anos, a AFL-CIO viu diminuir sua porcentagem de afiliados de 35\% para 10\% (Serrano-Jenkins, 1999). 
Quando se deu a discussão para a criação do Nafta, o processo que acabamos de descrever estava em pleno desenvolvimento nos Estados Unidos. O acordo de livre comércio entre Canadá, México e Estados Unidos foi aprovado em 1993, e rapidamente muitas empresas começaram a trasladar suas instalações para ao sul do rio Bravo, juntando-se às numerosas maquiladoras que já existiam na zona fronteiriça entre estes dois últimos países.

A AFL-CIO não participou muito ativamente na discussão e nos acertos prévios à sanção do Nafta. No entanto, quando a economia norte-americana mal começava a sair da recessão - o que não era ainda percebido claramente pela sociedade civil -, os trabalhadores emitiram um "voto castigo" àqueles representantes democratas das áreas de maior densidade obreira, o que fez o Partido Democrata perder a maioria em ambas as câmaras, situação que, como se mencionou anteriormente, repetiu-se nas eleições de 1996 e 1998, se bem que em menor escala. O resultado eleitoral de 1994 foi muito claro e serviu de pré-aviso: em 1993, quando o Congresso aprovou o Nafta, o presidente Bill Clinton contou com 40\% dos votos de seu partido (Washington Post, 1993); já para a aprovação da fast track em 1997 dispunha de apenas 20\%. Cabe destacar ainda que, quando em 1994 Clinton propôs que as disposições do Nafta - com seus novos acordos sobre trabalho e meio ambiente - se convertessem em precedentes para todas as conversações comerciais propostas, os representantes do Partido Republicano, mesmo sendo minoria, se bastaram para rechaçar a renovação da autoridade para negociar pela via rápida. Era a primeira vez que se negava tal autoridade a um presidente norte-americano.

Em 1995 a AFL-CIO mudou sua direção nacional, com a assunção de John Sweeney na liderança. Desde então, ocorreu uma série de mudanças de estratégia em relação aos acordos de livre comércio conduzidos pelo governo norteamericano, entre as quais o desenvolvimento de uma campanha muito mais intensa que em 1993 para enfrentar a política comercial de Clinton.

Mesmo tendo contado com o apoio dos sindicatos para as eleições, Clinton era visto por muitos dirigentes e trabalhadores sindicalizados como um presidente pouco confiável no tocante à defesa de suas fontes de trabalho e de seus direitos trabalhistas, independentemente da recuperação econômica conseguida durante sua administração e dos novos empregos criados. A crítica à sua administração recordava que boa parte dos novos empregos eram de menor nível salarial e profissional que os postos perdidos na indústria. O representante por Indiana Timothy Roemer, do Partido Democrata, destacava, por exemplo, que

We have low unemployment in Indiana, but thousands of people are hanging on by their fingernails to $\$ 6$ and $\$ 7$ an hour jobs, and they could be the first ones displaced. (...) I'm a free-trader, but I insist on fair trade (Washington Post, 1997a). 
A estratégia sindical esteve dirigida a duas categorias de legisladores, aqueles que tinham posições públicas sobre os temas trabalhistas e os membros do Congresso recentemente eleitos, todos os quais contavam com apoios financeiros para suas campanhas provenientes tanto de agremiações sindicais como empresariais. ${ }^{3}$

$\mathrm{Na}$ ocasião, o líder republicano Newt Gingrich atacou a postura sindical utilizando-se dos seguintes termos: "We are in very grave danger of losing our ability to compete in large parts of the world largely, frankly, because of the labor unions" (Washington Post, 1997a).

O líder da minoria na Câmara de Representantes, Richard Gephardt, por sua parte, assumiu a condução da oposição à autorização da via rápida, no que contou com o respaldo não somente dos sindicalistas mas também com o das organizações ambientalistas, de consumidores e de setores empresariais protecionistas, entre outras forças representativas.

$\mathrm{O}$ vínculo entre o comércio e o meio ambiente é mais recente que o existente com os sindicatos. Foi por volta do final da década de 80 e início da de 90 que os ambientalistas norte-americanos começaram a participar nas discussões. Sua oposição surgiu em resposta às críticas tecidas pelos sócios comerciais dos EUA, que afirmavam que as leis ecologistas norte-americanas eram "barreiras ocultas ao comércio". Isto provocou a reação tanto das organizações protetoras do meio ambiente como das de consumidores, que chegaram a considerar a liberalização comercial como "uma ameaça às leis nacionais e acordos internacionais tendentes a proteger a saúde, a seguridade e o meio ambiente" (Sela, 1998). Desde então essas organizações assumiram uma atitude muito mais combativa, formando-se uma aliança de fato entre organizações sindicais, ambientalistas, de consumidores, protecionistas e "os conservadores que temem que uma 'nova ordem internacional' intervencionista ameace a soberania dos Estados Unidos". Ouça-se o que David Bonior, representante democrata por Michigan, disse a respeito:

This was not a debate about protectionism versus free trade. Those of us who opposed this fast track have altered the terms of the trade debate ... (and) stand ready to work with the president to shape a new trade policy, one that addresses worker rights, food safety, consumer protection and the environment (Washington Post, 1997b).

Nesse cenário, numerosas entidades e organizações públicas e privadas fizeram campanhas algumas a favor e outras contra a aprovação da via rápida. ${ }^{4}$

O repúdio à autorização solicitada por Clinton levou Lori Wallach, da organização Public Citizen's Global Trade Watch, a afirmar que a vitória assinalava uma mudança para uma nova política comercial nos EUA e uma rejeição dos modelos do Nafta e Gatt. Por sua parte, Roberto Borosage, da Campaign for America's Future, declarou que o acontecimento era 
the beginning of the progressive struggle for the next decade... It is a statement that neo-liberalism that combines economic conservatism with a liberal social agenda is not where the Democratic Party is at (Washington Post, 1997b).

\section{Aproximação com as centrais sindicais do Cone Sul}

A derrota em 1997 dos partidários da autorização ao presidente dos EUA para fazer acordos sobre livre comércio mediante o mecanismo da fast track repercutiu profundamente no desenvolvimento das negociações para a criação da Alca.

No entanto, como assinala a representante da AFL-CIO para o Cone Sul, Zoveida Serrano-Jenkins, essa foi somente uma batalha. Para a sindicalista, "a guerra continuará seguramente" durante o mandato de George Bush Jr, o novo presidente norte-americano que assumiu em janeiro de 2001. Cabe recordar que o atual titular da Casa Branca leva o nome de seu pai, o ex-mandatário sob cujo mandato se pôs em marcha o acordo com o Canadá, se começou a negociar o que incluiu o México e que foi quem, em junho de 1990, lançou a idéia da "Iniciativa para as Américas", antecedente direto da Alca.

Porém agora a central sindical norte-americana está atuando - no dizer de sua delegada no Cone Sul - como "cão de guarda", já que "o Nafta é um modelo que não se deve reproduzir como surgiu nos anos 90", e a organização sindical tem medo de que a Alca vá na mesma direção:

la posición de la AFL-CIO hoy en día en relación al Nafta es que es um modelo que no se debe permitir que se reproduzca de la forma que se hizo en o Tratado con Canadá e México. Porque no había allí ninguna cláusula ni nada que pudiera darle cierta seguridad a los trabajadores, ya sea de Canadá, o de México, o de Estados Unidos, para que tuvieran cierto control de lo que estaba pasando, especialmente porque todas aquellas promesas que se hicieron para fortalecer los vínculos fue meramente comercial, dejando al lado, completamente, lo de la parte social e ambiental (Serrano-Jenkins, 1999).

Segundo a representante sindical, a ascensão de John Sweeney à frente da AFL-CIO implica uma mudança absolutamente fundamental, tanto na orientação política da central sindical como na estratégia a seguir. Definido o Nafta como um acordo negativo para os interesses dos trabalhadores norte-americanos, se propõe que a Alca não pode ser instrumentada da mesma forma; daí se inicia uma campanha nacional que primeiramente "freia" a autorização a Clinton e logo se começa a buscar aliados, transcendendo fronteiras e organizações.

Antes, porém, a nova direção sindical precisou "varrer a casa" dos ranços burocráticos que desde muitas décadas se haviam enquistado no movimento 
trabalhista organizado dos Estados Unidos. Além das denúncias sobre comportamentos divisionistas e ocasionalmente delituosos que recaíram sobre alguns antigos dirigentes da central, desconhecendo um riquíssimo histórico de lutas obreiras desenvolvidas ao longo e ao largo do território norte-americano desde os tempos da Guerra Fria, a AFL-CIO se alinhou com as posições políticas e ideológicas internacionais do governo de seu país. Proibidos e perseguidos os dirigentes de esquerda desde a época de Joseph Mc Carthy, os vínculos do sindicalismo norteamericano com o exterior estiveram impregnados durante 40 anos pelo conflito "Leste-Oeste", priorizando relações com aquelas centrais sindicais das Américas que comungavam com seus critérios.

\section{As centrais sindicais do Cone Sul e a globalização}

No Cone Sul do continente, pelo contrário, a posição ideológica dominante entre os sindicatos e as centrais foi geralmente, ao longo da história, de esquerda excetuado o caso argentino, onde essa corrente foi desalojada pelo Peronismo desde os anos 40 -, oscilando entre o anarquismo e o anarco-sindicalismo dos primeiros tempos das organizações gremiais e o alinhamento com os partidos comunistas da região - os quais geralmente estavam, a sua vez, alinhados com as posições da União Soviética - nos períodos prévios aos golpes militares que se desataram sobre a região nos anos 60 e 70.

À saída das ditaduras, e novamente com a exceção argentina, as tendências dominantes haveriam de estar novamente vinculadas a forças políticas e ideológicas de esquerda, ainda que diferentes das dos partidos comunistas, que perderam o protagonismo imediatamente após a implosão da União Soviética. Durante décadas, falar da AFL-CIO no Brasil, Uruguai, Chile e mesmo na Argentina era falar de "amarelismo" e de "agentes do imperialismo".

Porém, os anos 80 e, principalmente, os 90 , verão expandir-se rapidamente os efeitos da globalização planetária, tanto sobre a América do Norte como sobre a América do Sul. Tais efeitos, no que tange aos trabalhadores organizados, têm sido, quando menos, de geração de inseguridades sociais e instabilidade do trabalho. No caso do Mercosul, se produz a "subproletarização do trabalho, presente na expansão do trabalho parcial, temporário, precário, subcontratado, terceirizado" (Carvalho, 1997: 99).

Dentro desse contexto, predominando as políticas econômicas neoliberais em um e outro hemisfério americano, os acordos de livre comércio como o Nafta e o Mercosul se transformaram não somente em motivo de preocupação intelectual, senão que também vieram acompanhados de fortes mudanças nas relações de trabalho, da perda de grandes quantidades de postos de trabalho e das tradicionais certezas (sobre habilidades, salário, seguridade social, etc.) que, através de muitos anos, os trabalhadores de um e outro lado vinham conquistando. 
A priorização, por parte dos governos envolvidos, dos aspectos econômicocomerciais de ambos acordos e a ausência de tratamento das mudanças na dimensão social, decorrente dos acordos, moveram as forças sindicais do Norte e do Sul a tomar iniciativas tendentes a obter o reconhecimento de seus direitos e a eliminar o "déficit social" que os acordos apresentavam.

Nos Estados Unidos, a resposta da sociedade civil - da qual participaram organizações ecologistas e de consumidores, e não apenas sindicais - foi conseguir a implementação de acordos que melhorariam parcialmente essas carências nos âmbitos dos direitos dos trabalhadores e da proteção do meio ambiente.

No Mercosul, por sua parte, os representantes sindicais lutaram para que fosse criado e para ter assento no Subgrupo de Trabalho 11 (SGT 11), o qual não tinha poder deliberativo e passou a ser denominado de SGT 10, depois do Protocolo de Ouro Preto. O Foro Consultivo Econômico-Social (FCES) foi a outra instância onde os representantes da sociedade civil dos quatro países do bloco podiam ter alguma participação, limitada fundamentalmente às consultas sobre assuntos de seu interesse. O propósito de estabelecer um Protocolo sobre os Direitos Sociais não foi aceito pelos governos dos países membros, se bem que se avançou algo com a Declaração Sociolaboral, aprovada em dezembro de 1998 e que levou à criação da Comissão Sociolaboral em 1999, possibilitando assim que os trabalhadores tenham um foro tripartido onde seus problemas e contradições possam ser debatidos com os empresários e os governos.

\section{Rumo a uma nova aliança Norte-Sul entre trabalhadores?}

Dizíamos anteriormente que a AFL-CIO mudou sua estratégia de relacionamento com o exterior. Desde 1997, o Centro de Solidariedade da central norte-americana havia designado vários representantes para trabalhar em contato com as centrais sindicais da América Latina. ${ }^{5}$

Depois das lógicas desconfianças iniciais, começou-se um trabalho de cooperação que, baseado no respeito mútuo, passou a ser bastante intenso entre a AFL-CIO e as centrais da Coordenadora de Centrais Sindicais do Cone Sul (CCSCS), especialmente com aquelas organizações com as quais antes tivera fortes discrepâncias ideológicas.

Entendendo que o problema da globalização afeta a todos - trabalhadores sindicalizados e não sindicalizados, consumidores, ecologistas, enfim a sociedade civil toda -, que os direitos trabalhistas devem ser defendidos em todas as frentes e em todas as regiões e que tanto o Mercosul, durante sua implementação, como a Alca, na forma como vem sendo negociada, carecem de propostas positivas sobre a dimensão social da integração, a colaboração oferecida pela central sindical norte-americana tem-se orientado fundamentalmente para o trato desses temas. 
Inicialmente reunidas para tratar os temas mais abstratos da globalização, as centrais paulatinamente foram formalizando o trabalho coordenado por setores de atividade. Assim, em dezembro de 1999 a CCSCS celebrou em Montevidéu uma Cúpula Sindical do Mercosul, onde estiveram representados 16 setores (bancários, de transportes, trabalhadores agrícolas, da construção, etc.), além de um grupo formado por mulheres sindicalistas que analisaram seus problemas comuns desde a perspectiva de gênero. A CCSCS, como vimos anteriormente, trabalhou duramente para conseguir a implementação tanto da Declaração Sociolaboral do Mercosul como da FCES. Em ambos os casos contou com o apoio da AFL-CIO.

A nova estratégia da central sindical norte-americana inclui também o estabelecimento de maiores e mais estreitos contatos com organizações da sociedade civil de diversas origens e temáticas. O protesto realizado em Seattle, EUA, por ocasião da reunião da Organização Mundial do Comércio (OMC), em novembro e dezembro de 1999, e a participação no Fórum Social Mundial, realizado em Porto Alegre, Brasil, em janeiro de 2001, de maneira simultânea com a reunião do Foro Econômico Mundial de Davos, são outros exemplos dessa estratégia. Por isso é que, procurando estabelecer uma rede a mais ampla possível, a AFL-CIO tem convidado dirigentes sindicalistas do Sul:

Para la AFL-CIO entender un poco las realidades de los compañeros del Sur, y también para tener un diálogo de cómo pude desarrollarse una estrategia que para que este tratado comercial (...) pueda ser frenado hasta haya una posición, una propuesta de parte de los diferentes grupos de la sociedad civil, incluyendo el sindicalista (...) para que los diferentes sectores de la sociedad civil puedan incidir en relación a cómo se va a dar ese proceso de libre comercio (...) la AFL-CIO tiene un compromiso real y transparente de apoyar al sindicalismo, al movimiento sindical en Sudamérica, para que pueda tener una fortalece y pueda tener un apoyo a nivel de toda la sociedad civil para que pueda, entonces, lidiar efectivamente con esto que se avecina (Serrano-Jenkins, 1999).

Esta mudança tão drástica nas relações sindicais Norte-Sul, a partir da qual as centrais - que até há bem poucos anos se viam como inimigas ou, na melhor das hipóteses, com muito receio - sentam-se à mesma mesa para dialogar, elaborar estratégias conjuntas e colaborar economicamente para a concretização das tarefas programadas, é um fato novo, inédito no sindicalismo classista do Cone Sul. Este tipo de colaboração solidária entre as centrais do Norte e do Sul vem reforçar mutuamente as atividades que a AFL-CIO, em seu país, e a CCSCS, no Mercosul, vêm desenvolvendo contra a Alca e os acordos de livre comércio.

Tais acordos têm sido pensados exclusivamente desde a ótica governamental e empresarial, deixando de lado seus efeitos sobre o emprego, a seguridade e o nível de vida de seus cidadãos. Sem embargo, começa a haver mudanças de rumo também no âmbito governamental e empresarial. 
Uma das razões que está por detrás da posição sustentada pelo Mercosul a partir da reunião ministerial da Alca realizada em 1997 em Belo Horizonte, tendente a frear a implementação da Alca enquanto não estejam dadas as condições relativamente similares de competitividade da produção sub-regional, justifica-se porque uma maior abertura comercial, como a que foi proposta pelos Estados Unidos, suporia que os bens e serviços norte-americanos entrariam em maior quantidade e diversidade no mercado local.

De acordo com os diferentes níveis de sofisticação e tecnologia de uma e outra produção, especialmente nos bens do setor industrial, esta abertura seria prejudicial para as empresas do Mercosul. Precisamente, as que maior preocupação expressam são aquelas onde estão os empresários mais empreendedores e dinâmicos, nos quais poderá basear-se um futuro manufatureiro mais competitivo da sub-região. Ao se abrir o mercado interno à competição norte-americana, essas empresas se veriam desalojadas, o atual parque industrial do bloco sub-regional se desestruturaria ainda mais e se agravariam fortemente as já más condições de emprego, afetando os trabalhadores mais qualificados. Isso é motivo de preocupação de governos, empresários e trabalhadores do Mercosul.

A isso se agrega o debilitamento das posições do Mercosul, derivado das sucessivas crises ocorridas de 1999 a 2001 no seio dos governos de alguns de seus membros e associados. Por um lado, estão os sinais ambíguos que, do ponto de vista tanto político como econômico, dão as autoridades argentinas desde que Fernando de la Rúa assumiu como presidente, sinais esses agravados a partir de abril de 2001, com a ascensão do comando da economia por parte do ministro Domingo Cavallo. Por outro, o discurso nitidamente contrário ao Mercosul e ao Brasil e a favor dos Estados Unidos e da Alca do novo presidente do Uruguai, Jorge Batlle. Por último, está também a já conhecida atitude do Chile, um associado especial do Mercosul que, no entanto, há alguns anos, joga com a possibilidade de incorporar-se ao Nafta ou, ao menos, de ter uma zona de livre comércio bilateral com os Estados Unidos, zona que está sendo novamente negociada, com dificuldades, desde dezembro de 2000.

Todos esses fatos concorrem para isolar mais o Brasil, que é o país que mais luta frente ao avanço da Alca e um dos que mais resiste às pressões dos EUA. Por outro lado, vão de encontro às posições defendidas pelas organizações sindicais do Norte e Sul das Américas.

Para aqueles setores que no Mercosul se opõem à criação da Alca, fica claro que, sem fechar acordos sobre quais setores seriam resguardados da competição externa e sem o estabelecimento de contrapartidas adequadas para compensar as quebras, fechamentos e perda de fontes de trabalho que ocorreriam com a criação da área de livre comércio, o Mercosul não estará em condições de abrir-se aos Estados Unidos. Os EUA são a maior potência mundial, a economia mais globalizada e a mais globalizadora em seu mover-se. Num futuro em que não 
se descartam prováveis conflitos comerciais entre blocos, esse gigante claramente pretende assegurar sua própria reserva de mercado através de uma espécie de "regionalismo globalizado" no qual, segundo a perspectiva de diversos setores econômicos, políticos e sociais do Mercosul, é quem mais tem a ganhar e menos a perder.

Por isso, as correções de rumo que começariam a esboçar-se no Mercosul e eventualmente na Alca, encaminhadas por iniciativa dos trabalhadores, podem estar iniciando uma nova aliança estratégica entre governos, empresários e trabalhadores do Mercosul.

Mas, simultaneamente, também se estaria gestando uma outra aliança, de similar nível de importância para os trabalhadores, entre as centrais sindicais do Sul e a central norte-americana. Neste caso, talvez, poderia estar-se iniciando uma nova forma de "internacionalismo dos trabalhadores sindicalizados", preocupados agora, fundamentalmente, com os efeitos perniciosos da globalização sobre seus direitos trabalhistas e sobre suas condições de vida, antes que com as questões de caráter ideológico que foram motivos de preocupação e enfrentamento dos dirigentes sindicais em décadas passadas.

Uma e outra aliança iriam em uma direção similar: frear a implementação da Alca, dotar o Mercosul das condições necessárias para aumentar sua competitividade internacional sem afetar os níveis de produtividade, emprego, salário e bem-estar, e estabelecer uma área de direitos sociais que os acordos de livre comércio, tal como foram pensados e inicialmente instrumentados, não têm incorporado. Isso possibilitaria que, tendo o tempo diminuir os desequilíbrios atuais nos níveis salariais e nas condições de trabalho do Norte e do Sul, se preservassem os níveis de trabalho internos, sendo fatores de igualação que reduziriam as diferenças de competitividade atualmente existentes.

\section{Conclusões}

As organizações sindicais e sociais que, em nível mundial e continental, enfrentam o processo de globalização, considerando-o uma fase perversa e perniciosa vivida pelo desenvolvimento do capitalismo no apagar-se do século XX, têm alcançado, a partir de Seattle, uma repercussão internacional muito ampla, resultado de sua ação coordenada e de um renovado ativismo político e social. Paradoxalmente, tamanha vitalidade é facilitada pelo desenvolvimento de um dos instrumentos mais importantes da globalização: o acelerado e espetacular desenvolvimento das telecomunicações.

No âmbito da Alca, estas organizações sociais ainda não lograram idêntica repercussão, se bem que a similitude de problemáticas dos trabalhadores do Norte e do Sul das Américas tem determinado o início de ações conjuntas. 
Neste novo protagonismo dos movimentos sociais, as organizações sindicais ocupam lugar destacado, em particular a central norte-americana AFL-CIO, que reivindica e defende com um novo vigor os direitos de seus trabalhadores afiliados. Esta defesa, sendo protetora dos interesses dos trabalhadores norte-americanos, é, em boa medida, coincidente com as posições que sustentam as centrais sindicais classistas do Mercosul, agrupadas na Coordenadora de Centrais Sindicais do Cone Sul.

No que diz respeito às organizações sindicais, que são uma parte significativa da sociedade civil, os fatos parecem indicar que estaria nascendo uma nova forma de "internacionalismo sindical" entre as até há pouco tempo ideologicamente antagônicas centrais de trabalhadores dos Estados Unidos e dos países do Cone Sul.

O fim da Guerra Fria e a subseqüente hegemonia mundial praticamente exclusiva exercida pela nação norte-americana, somados à insegurança que o processo de globalização acarreta ao trabalho tanto no Norte como no Sul, teriam ajudado a eliminar (ou ao menos a relativizar) os desencontros anteriores de tipo ideológico.

Saiu, assim, à luz a semelhança de vicissitudes que vivem atualmente os trabalhadores de um e outro hemisfério, acossados pelas incertezas oriundas da precarização e terceirização do emprego, o risco do desemprego, o rebaixamento salarial e a conseqüente perda massiva de afiliados sofrida nas últimas décadas pelas referidas centrais sindicais, fato que claramente as debilita e lhes subtrai poder de pressão.

Os novos laços estabelecidos entre a AFL-CIO, por um lado, e as centrais sindicais do Cone Sul, pelo outro, estão abrindo um novo caminho nas relações Norte-Sul, desta vez em nível de organizações que são representativas de importantes setores da sociedade civil. Essas centrais sindicais, se é que já não exercem, estão em condições de exercer uma apreciável influência na determinação das políticas nacionais e internacionais de seus respectivos governos, especialmente em tudo aquilo que se refere ao âmbito do trabalho dentro de uma provável futura zona de livre comércio interamericana.

Novamente o paradoxal está presente: o sindicalismo norte-americano está preocupado fundamentalmente com a possibilidade de as empresas de seu país fecharem suas fábricas e se instalarem no exterior, diminuindo os postos de trabalho, os salários e as condições de vida de seus afiliados. As centrais sindicais do Mercosul, por sua parte, estão preocupadas porque a concorrência de produtos importados tem já determinado o fechamento de numerosas plantas industriais e a ruína de muitos agricultores, acabando também com fontes de trabalho que são de muito difícil reposição nestes tempos de globalização e, em conseqüência, afetando os mercados de emprego, os níveis salariais e o bem-estar dos trabalhadores do Mercosul. 
Nesta nova aliança sindical, cada parte defende, conservadoramente, os interesses de seus representados, os trabalhadores do Norte e do Sul, através da adoção de posições e do apoio a medidas que, sendo de conteúdos diferentes, são convergentes no resultado final.

É nesse sentido que se deve interpretar, então, esta emergente Aliança Social Continental que está surgindo entre organizações sindicais e sociais do Norte e do Sul. Esta aliança se viu reforçada na Segunda Cúpula dos Povos das Américas, realizada em abril de 2001 em Quebec, Canadá, por ocasião da Terceira Cúpula das Américas, cujos participantes, os 34 Chefes de Estado dos países envolvidos na Alca, se viram confrontados pelas posições nela adotadas. E tanto maior é o reforço quando simultaneamente se vai processando também, com finalidades similares, uma Aliança Social Mundial, que teve na reunião de Porto Alegre um marco muito importante para sua concretização.

Este é o novo caminho trilhado pelas diversas organizações sociais que, ao se defrontarem com a evidência dos múltiplos efeitos negativos que o processo de globalização acarreta, decidiram sair a campo e propor alternativas que ao menos atenuem os custos sociais aos cidadãos mais desprotegidos do Norte e do Sul, e lhes permitam preservar tanto suas fontes de trabalho como sua dignidade humana. Julho de 2001

\section{Notas}

1 Em 2000, a denominação Fast Track Authorithy mudou-se para Trade Promotion Authority (TPA).

2 Situação curiosa se deu em maio de 2001, quando o senador Jim Jeffords, eleito em Vermont pelo Partido Republicano, abandonou o partido, declarando-se independente desde então e possibilitando que o Partido Democrata, sob a liderança de Tom Daschle, passasse a ter novamente o controle do Senado. Quase simultaneamente, seu colega do Arizona John McCain, que foi précandidato em 2000 enfrentando George Bush Jr., anunciou atitude idêntica, possivelmente para lançar-se novamente como pré-candidato presidencial em 2004.

3 Por ocasião do debate de 1998, foi publicada a lista de tais financiamentos, de modo a submeter ao juízo da cidadania a votação de cada membro do Partido Democrata (Legi-slate, 16/1/98).

4 Entre aquelas favoráveis à autorização se destacam: a Casa Branca, America Leads on Trade Coalition, Chamber of Commerce. Em torno dessa mesma posição se agregam numerosas personalidades da política e do establishment norte-americano: Gerald Ford, Bob Dole, Clyde Prestowitz, Mickey Kantor, Brent Scowcroft, William Daley, etc. Entre as contrárias à autorização estão: AFL-CIO, Public Citizen's Global Trade Watch, UNITE, Sierra Club, The National Farmers Union, The Human Society e Pure Food Campaign.

5 Quando da entrevista (1999) com Serrano-Jenkins, havia seis representantes da AFL-CIO trabalhando na região, sendo ela responsável pelo Cone Sul (Mercosul mais Chile e Bolívia), enquanto Caroline Castings se ocupava do Brasil. Os outros representantes estão no México (1), América Central e Caribe (2) e área andina (1). 


\section{Bibliografia}

CARVALHO, Célio Almeida de. "O processo de integração regional e as propostas do Movimento Sindical para o Mercosul.” Tese de Mestrado. Pontifícia Universidade Católica. São Paulo, 1997.

MINIÁN, Isaac. Cambio estructural en las economías avanzadas: temas para el debate sobre estrategias de desarrollo. CIDE, México, p. 37-62, 1989.

. Cambio estructural en los países avanzados: deterioro de las tendencias a la relocalización industrial. CIDE, México, p. 13-28, 1990.

SERRANO-JENKINS, Zoveida. Montevideo, diciembre de 1999. Entrevista, por Wilson Fernández.

SISTEMA ECONOMICO LATINO AMERICANO (SELA). Opciones de los Estados Unidos en el Área de Libre Comercio de las Américas. Secretaría Permanente del Sela. The Trade Forum of the Americas. Febrero, 1998.

USTR. Report to the Congress: Recommendations on Future Free Trade Area Negotiations. Reports Issued by the Office of the United States Trade Representative and Related Entities. September $25,1997 b$.

USTR. Study on the Operation and Effect of the North American Free Trade Agreement. Reports Issued by the Office of the United States Trade Representative and Related Entities. 1997a

WASHINGTON POST, THE. HOUSE Approves U.S. - Canada-Mexico Trade Pact on 234 to 200 Vote, Giving Clinton Big Victory. Por Kenneth J. Cooper, Washington Post Staff Writer. November 18, 1993. Edição digital.

. NO TRADE Agreement Among Democrats. Por Thomas B. Edsall and John E. Yang, Washington Post Staff Writer, November 11, 1997a. Edição digital.

. ON TRADE, U.S. Retreating into globalphobia. Por Steven Pearlstein, Washington Post Staff Writer, December 8, 1997b. Edição digital.

WASHINGTON TIMES, THE. WHO lost fast-track? Editorial. November 11, 1997. Edição digital.

\section{Resumo}

Apoiado em entrevista com dirigente sindical e em artigos publicados em jornais de Washington (EUA), além de outras fontes bibliográficas, o texto examina os rumos que as organizações da sociedade civil das Américas, em particular as centrais sindicais, vêm trilhando nos últimos anos. Segundo enfoca, para defender os trabalhadores de seu país das ameaças ao trabalho advindas com a globalização, o regionalismo econômico - em especial a Alca - e o avanço tecnológico, a central norte-americana American Federation of Labor - Congress of Industrial Organizations mudou radicalmente suas estratégias. Ela agora, em vez de tentar barrar os acordos de livre comércio, tem procurado limitar a autonomia governamental na negociação dos mesmos. Ao mesmo tempo, vem buscando uma maior articulação com as centrais da América Latina. Essa aproximação, ao que parece, está dando origem a um novo e promissor "internacionalismo sindical”. 
Abstract

Based on an interview with a trade union leader, on American newpapers articles published in Washington, D.C. and on other bibliographical sources, the article analyzes the trends followed during the last years by the American Civil Society organizations, specially the trade unions confederations. In order to defend the American workers of the treats linked to globalization, economic regionalism specially the Free Trade Area of the Americas (FTAA) - and technological progress, the American Federation of Labor-Congress of Industrial Organizations (AFL$\mathrm{CIO}$ ) changed radically its strategies. Now, instead of fighting against the free trade agreements, it tries to limit the governmental autonomy into these negociations. At the same time, it promotes a greater articulation with Latin American trade unions confederations. This approximation favours the beginning of a new and hopeful "trade union internacional position".

Palavras-chave: Alca, AFL-CIO, alianças Norte-Sul entre centrais sindicais Key Words: FTAA, AFL-CIO, North-South alliances between trade unions confederations 